\title{
Barriers to maternal health service use in Chikhwawa, Southern Malawi
}

\section{Kambala ${ }^{1 *}$, T. Morse ${ }^{1,2}$, S. Masangwi ${ }^{1}$, P. Mitunda ${ }^{1}$}

1. University of Malawi, The Polytechnic, Private Bag 303, Blantyre 3, Malawi.

2. University of Strathclyde, Rottenrow, Glasgow, G4 ONG,

*Correspondence to: christabel_kambala@yahoo.com

\section{Abstract}

\section{Introduction}

Research was conducted to get a community's perspective on the factors contributing to continued maternal and neonatal deaths. The aim of the study was to identify and understand experiences, perceptions and needs of the community on maternal health service utilization.

\section{Methods}

Qualitative data was obtained through focus group discussions with community leaders, women, men and youth in the catchment areas of three remote health centres. A total of fourteen focus groups were held: three each with community leaders, men, women, boys and two with girls.

Data was transcribed and analyzed manually through the use of thematic analysis.

\section{Results}

The discussions revealed the following as barriers to maternal health service utilization: walking long distances to access health facilities, lack of midwives, lack of or insufficient items to be used during delivery, long stay and rude health personnel. Seeking help from Traditional Birth Attendants (TBAs) during delivery was a common option because TBAs are within reach, do not demand many items for delivery, and treat the women with respect. Conclusion

This study suggests some factors that are contributing to the high burden of maternal deaths in Malawi. Interventions should be developed and implemented to improve the barriers reported.

\section{Introduction}

The Millennium Development Goal (MDG) number five, set to reduce maternal mortality in the world, is proving hard to attain in most developing countries ${ }^{1}$, although most maternal deaths are preventable ${ }^{1-2}$. Every year more than half a million women die due to complications of pregnancy and child birth, ninety nine percent (99\%) of these live in the developing countries.

Half of all maternal deaths occur in sub-Saharan Africa and another third in Southern Asia and together they account for $85 \%$ of all maternal deaths ${ }^{1}$. Although the proportion of births attended by skilled health workers in developing regions has increased from 53\% in 1990 to $61 \%$ in 2007, more than half of all births still take place without the assistance of trained personnel in Southern Asia and subSaharan Africa ${ }^{3}$. Pregnancy early in life contributes to the estimated 70,000 maternal deaths among girls aged 15 to 19 years ${ }^{1}$. An infant's risk of dying in his or her first year of life is $60 \%$ higher when the mother is under age 18 than when the mother is 18 or older ${ }^{1}$.

Malawi continues to have a high maternal mortality ratio of 807/100,000 live births, well above the 2015 MDG target of $560 / 100,000^{4,5}$. Ministry of Health through the Sector Wide Approach (SWAp) PoW (Program of work) as part of the Essential Health Package (EHP) have set in place mechanisms to provide reproductive health services and strengthen the entire health system ${ }^{6}$. Furthermore, an action oriented Road Map for accelerating the reduction of maternal and neonatal mortality and morbidity has been developed ${ }^{7}$. The Road Map has specified various guiding strategies for policy makers, development partners, training institutions and service providers ${ }^{7}$.

Responding to the Road Map, Scotland Chikhwawa Health Initiative (SCHI), a consortium of The University of Strathclyde, University of Malawi and Chikhwawa District Health Office has been awarded a three year grant from the Scottish Government International Development fund to start a reproductive health programme in Traditional Authority (T/A) Chapananga in Chikhwawa district, Malawi. The goal of the project is to improve maternal health services by reducing maternal and neonatal morbidity and mortality in the area. Therefore, it seeks to strengthen skilled delivery at health facilities, and discourage community based deliveries, that normally contribute to maternal deaths due to complications. This is to be achieved through health worker capacity building, facility improvements, community based education and development.

A survey conducted among health personnel (clinical officers / medical assistant and nurses), working in health facilities and community health personnel (Health Surveillance Assistants (HSAs) and Traditional Birth Attendants (TBAs) (nonprofessional women who conduct deliveries in the community) suggests that maternal and neonatal deaths continue to occur in the targeted areas ${ }^{8}$. Of forty one HSAs interviewed; half reported witnessing maternal and neonatal deaths in their communities from 2009 to the time of the interviews, September 2010. Similarly, of twenty five TBAs interviewed; $20 \%$ and $12 \%$ reported witnessing neonatal and stillbirths respectively in 2010 alone and $16 \%$ of them witnessed maternal deaths between 2009 and $2010^{8}$.

Our study was conducted among community members to gain an in depth understanding of what could be fuelling the continued maternal and neonatal deaths in the area. In particular, the study sought to better identify and understand reproductive health experiences, perceptions and needs. The results of this study will influence the information and strategies to be included and used in the planned maternal health interventions.

\section{Method}

Focus group discussions were conducted in Traditional Authority (T/A) Chapananga, Chikhwawa district. The study targeted the catchment areas of three remote health centres of Chithumba (population 7, 331), Gaga (population 18,893) and Chang'ambika (population 6,868 ) where the project is to concentrate.

An interview guide was developed to probe underlying beliefs and practices about maternal and neonatal health among community members, and also to confirm and explore more the survey data reported above ${ }^{8}$. Before facilitating the Focus Group Discussion (FGDs), the team carried out a pretest 
at Kakoma Health centre's catchment area. This area has the same characteristics as the targeted areas. The exercise provided an opportunity to practice, clarify and amend some questions and shape the final interview guide.

The focus groups were each scheduled for one hour and were conducted for three days, in October, 2010. Two people facilitated each focus group, where one led the discussion and the other took down notes. The sessions were recorded using digital voice recorders for post FGD reference.

Five focus groups were conducted in Gaga, five in Chang'ambika, and four in Chithumba catchment areas, making a total of fourteen groups. The groups were made up of: community leaders ( $>25$ years), women $(>25$ years), men ( $>25$ years), boys (15-24 years) and girls (15- 24 years). Each group had 8-12 participants so that a total of about one hundred and forty respondents took part in the fourteen focus groups. The groups were divided according to level of authority, sex and age. The divisions were necessary so that people discuss freely and confidently, because reproductive health issues are mostly sensitive. Also, according to Malawian culture, community leaders are well respected members of society hence a separate group of community leaders. Data was transcribed and analyzed manually through the use of thematic analysis.

\section{Results}

Of the one hundred and forty four participants, there were forty five men, forty five women, thirty boys and twenty girls. The number of years of schooling completed ranged from none to form four amongst women and men participants. While years of schooling for boys and girls ranged from standard one to form four. While all the youth were single and still in school, marital status of the women and men ranged from married to divorced, single or widowed.

The following summary of findings provides the themes and insights that emerged based upon seven recurring themes:

1. General health problems

2. Sexual reproductive health problems and risks

3. Maternal health problems

4. Community deliveries

5. Decision making about going to the health facility

\section{General Health Problems}

Participants were asked to describe the general health problems that people face in the area.

Problems mentioned were long distances to access health facilities, rude health personnel,corrupt health personnel, lack of safe drinking water, and hunger leading to malnutrition. Most or all these sentiments were shared by all the focus groups across the subjects.

\section{Long distances}

All the participants in all focus groups mentioned long distance to health facilities as the biggest problem as people walk or cycle long distances when they are ill. On average the time was estimated as three to four hours walk. One participant indicated that: "When you start off at 6 a.m. you may arrive at the hospital at around 10 a.m." This length of time was reported in most focus groups.

\section{Rude health staff}

The participants expressed that they were mistreated by health personnel when they go to the hospital. For example one participant said: “The doctor is rude, he doesn't want to help us, he insults us every time we go there, and he says he cannot treat two people from the same family, saying that two people from the same family cannot fall sick at once".

Another participant added that: "These health personnel, apart from not attending to two people from one family, they also refuse to treat for multiple problems. They will normally say that, one person can not suffer from two diseases e.g. headache and stomachache". Therefore, if one has two complaints she/he will only be allowed to be treated for one and will be told to come next time for the other problem.

\section{Corrupt health workers}

The majority of participants felt that the health workers in their areas were corrupt. For example, participants expressed concern over the misuse of an ambulance, drugs and charging for growth monitoring. One participant indicated that: "If we call for an ambulance, we are requested to pay for it. Alternatively, we are told to buy fuel in order to transport a sick person to Mwanza district hospital. Most of the times we don't have money, as a result deaths occur that may have been prevented if we had been given the ambulance for free. It is worrying because we actually see the ambulance doing business; it goes to Mozambique to carry packs of beer for sale while people's lives are left in jeopardy".

Others indicated that health workers sell drugs to Mozambicans at the expense of Malawians. So that a number of Malawians have also started buying the medicine: "If you go to the hospital without money, you will not be helped", " health workers are selling mosquito nets and drugs to Mozambicans, these health workers are getting rich here, for instance one health worker had stolen 16 mattresses, fortunately he was taken by police to answer charges."

One community leader at Chang'ambika, indicated that often times, the HSA charges women who take their children for growth monitoring. They reported that they are told to pay the HSA K200.00 (approx. \$1.5) before weighing the children.

\section{Sexual reproductive health challenges and risks}

Overall the participants mentioned a number of challenges that put their reproductive health at risk. While the youth expressed scarcity of condoms and lack of knowledge on family planning as some of the challenges, the majority of women indicated lack of antenatal care, poor delivery services and postnatal care at the health centres as challenges. The most commonly mentioned risk regarding lack of antenatal care was lack of awareness on how the baby was positioned which may become a risk if she goes and delivers at the TBA. Another risk associated with community delivery that was reported was the possibility that a woman may lose a lot of blood during delivery. If this occurs the TBA may not be able to rectify the problem. The most common risk associated with postnatal care was infection. Groups indicated that if infection occurred after a community delivery at the TBA then the mother may die.

\section{Maternal health problems}

In addition to general health problems, groups were also asked about the problems they faced specifically on maternal health. Issues that came out were lack of mid-wives, health staff chasing pregnant women away, lack of or insufficient items required by the hospital during delivery, long stay in the hospital. 


\section{Lack of mid-wives}

A majority of the participants expressed that lack of midwives in their health centres was a big problem: "we have a hospital but no doctor at the health facility to help pregnant women. At first pregnant women used to seek help from TBAs but now with the ban, people are going to the health centre but they are not getting proper help, we need a female doctor here, we hope that if they can give us a female doctor, our problems may lessen."

\section{Health staff chasing away patients}

Some areas of Chikhwawa are closer to health facilities in Mwanza district than Chikhwawa. Many participants indicated that, despite travelling long distances to health facilities in the neighboring Mwanza district, they are chased away, saying that: "You are from Chikwawa district, why don't you go there?" They reported that they were left to give birth under a tree or in a toilet, so that guardians are the ones left to help the women. One woman said that: "We are ashamed when delivering because in such circumstances we lack privacy, everybody including men witness the birth."

\section{Lack of or insufficient items for use during delivery}

Others expressed that women were left unattended if they report late to the hospital already in labour, or if they have not brought the necessary items required at the hospital during delivery, like plastic sheet of paper, a basin, thread, razor blade, four zitenje (cotton wrappers) and candles (where there is no electricity). Lack of these materials was seen to be a huge hindrance, so that people are barred from giving birth in the maternity wards and they end up delivering outside the hospital with assistance from guardians. Alternatively they go back to their communities and seek assistance from TBAs.

One participant said that: "You don't have a basin, thread, razor blade, four wrappers, and then what do you do? Better go to a TBA. As long as you have a razor blade and a plastic sheet of paper you will be helped. Demands at the hospital are huge; hospitals now are for rich people. Poor people will die under a tree!" Another participant said, "Also if you lose a lot of blood on the way to the hospital, they don't help you because you have gone there late." Another woman said: "It's not even that, I went there in good time because I know I lose a lot of blood during delivery. One time I went there (at the hospital), I gave birth and I was losing a lot of blood as is the case, I told the nurse on duty about this but she did not do anything, she left. The next thing I heard was that she has gone for a workshop somewhere. I was discharged the next morning without any drugs; I came back here very weak and people were worried, but by the grace of God I got better."

\section{Long stay in the hospital}

The FGDs probed further on the reasons why women report late to health facilities. One respondent said that "it is important for one to go to the hospital in good time when one is eight months pregnant, but this is practically difficult." When asked how difficult, one participant said that: "People are going late to the hospital because they need to source and accumulate a number of items to use during delivery as demanded by the hospitals, as well as food and money to use while at the hospital. This may not be feasible because, one considers the time she is going to stay there, the resources needed and who is going to look after other small children left behind".

\section{Community deliveries}

Although initially participants denied that community deliveries are still taking place, it was quite evident that deliveries still take place in the communities and the FGDs sought to find out more on this area.

Some women felt that it was more convenient and respectful to give birth at the TBA than the hospital. Those favoring the services of TBAs indicated that they do so because they do not have to be far away from home for so long; also the TBAs do not demand many items and do not abuse them verbally like they do at the hospital.

One respondent said that: "I've never delivered at the hospital, all my four children were delivered at TBA, and I don't have any intention of going to the hospital should I become pregnant again, because of how people are mistreated there." Another participant added: "At the TBA, am respected and pampered but when you go to the hospital they will insult you".

However, there were others who condemned the practice of delivering at TBAs; they felt that it was dangerous because of complications that may arise during delivery.

And some community leaders blamed health workers for failing to give pregnant women right estimations as to their Expected Date of Delivery (EDD) "sometimes nurses miss the EDDs for these women and may go in labour long before. As a result women go to the hospital very late and some deliveries take place at home before leaving for the hospital".

\section{Decision making about going to the hospital}

Generally, decision making about going to seek health services was believed to be made by the man in the house. This was mostly indicated among the women. One woman asked that: "If the man doesn't give consent, who is going to take you there? You need him to take you there on a bicycle and also that he should be going to see you, and take with him material and financial support the period you will be in the hospital". However, men expressed that they do not make decisions independently; decisions are made jointly between them (the men) and other respected older members of the family.

\section{Discussion}

Various factors were perceived by the participants as barriers to maternal health service use. The "barriers" identified are especially useful in explaining why the target area continues to have maternal and neonatal deaths.

The study identified long distances to access health centres as one factor that hinders pregnant women to use antenatal clinics (ANC), delivery and postnatal care. This finding concurs with several other studies conducted in Malawi and other developing countries such as Uganda, Cambodia, and Philippines which found long distance as barriers to the use of antenatal clinics, delivery and postnatal services ${ }^{1,3}$. Long distances forces women to seek assistance from nonskilled service providers. Consequently the most commonly utilized service is the TBAs because they are situated within their reach.

Another finding in this study was that Traditional birth attendants were favoured by most participants not only because they are within reach but also because the women will not stay away from home for a long time and the TBAs do not demand more items required for delivery than at 
the hospital. The length of stay and demand for materials needed for delivery at the hospital then was a barrier to the use of health facilities during delivery. This study agrees with a study conducted in Cambodia that established length of stay as a deterrent to health care utilization ${ }^{1}$, and also that hospital requirements deterred women from using ANC services in Uganda ${ }^{1}$.

One other finding in this study is that people perceived lack of midwives at health centres as a barrier to health facilities use. Pregnant women saw no need of going to the hospital if no professional person is to attend to them. As a result women seek help from TBAs since they are the only available option. However, this has led to an increase in the number of untrained TBAs in the target area. As long as they can cut the umbilical cord, other women will go to them for assistance. This practice is worrisome but inevitable since where there is no alternative, women find it easier to go to next door neighbors than going to seek help from faraway places. Probably this shows lack of health values in people. People need to be taught to value their health, so that they can make better decisions about their health". But then, to successfully reduce maternal mortality especially in low income countries, there is need to have availability of skilled birth attendants located within communities, availability of birthing facilities with established, effective and efficient referral links at community level ${ }^{10-11}$ and adequate resources in the health facilities ${ }^{12}$.

Although the need for pregnant women to use maternal health service was appreciated, participants indicated that it is also important that the health workers treat them with respect and preserve their dignity. Many participants bemoaned the behaviour portrayed by some health workers who shout and insult them in labour wards. As such availability of midwives is not enough but also the way that women are handled at these facilities will determine how far women will utilize the health facilities. The more patients are mistreated, the more they become dissatisfied and the more they tend to shun away from its utilization. This study concurs with a study by Ankunda et al, 2007 cited by World Health Organization (WHO), 2010 which established that one reason for low ANC utilization was rude health staff ${ }^{1}$.

Rude behavior by health workers towards patients may result from their being exhausted from overwork due to shortage of staff, poor facilities and lack of resources. Other participants understood this as a challenge on the part of the health workers. As stated by other participants during our study, they felt sorry for the health personnel at Gaga health centre who had huge workloads due to huge numbers of patients both on maternity and those with general illnesses. A study on the implications of the shortage of health professionals for maternity health in Sub-Saharan Africa ${ }^{13}$ showed that increased workload of health staff affects the quality of patient care. It established that inequitable distribution of maternal health professionals reduces the number of facilities equipped to offer emergency obstetric care 24 hours a day. This is the scenario in the study area. Since the area is remote most health workers do not want to work there and this escalates the problem of shortages of staff and addressing it is a big challenge.

Among the three health centres only one has a mid wife, and as such it cannot offer 24 hours emergency obstetric care because the midwife is also responsible for the antenatal and other consultations at the health centre. Studies have shown that when health staff do tasks they are not trained in, it becomes a challenge ${ }^{13}$. Consequently, this problem influences maternal deaths as observed in Pakistan where staffing patterns of peripheral facilities at the district level found to be significantly associated with maternal mortality ${ }^{14}$.

\section{Conclusion}

Looking at these findings, the SCHI should seek to develop and implement interventions to improve the barriers associated with maternal service utilization and the attitudes of health workers. In particular, it is recommended that interventions should be formulated in order to reduce risks associated with birth; promote improved client behaviours in health workers that lead to reduced risks during delivery, increase staffing and improve health facilities. Further, TBAs should be included within the programs as they are of good standing within the community and their skills can be utilized.

It is a challenge to motivate health staff to go and work in remote rural areas. The system of using incentives as a means of attracting people to work in the rural areas does not seem to work.

There is urgent need of establishing other ways of motivating health workers to go and work in rural areas. Without addressing this problem, rural areas will remain perpetually deprived of adequate health services.

Allegations of corrupt practices such as; requesting patients to pay or buy fuel in order to use an ambulance; making business with the ambulance like ferrying packets of beer from Mozambique to Malawi for sale; health workers selling drugs and mosquito nets to Mozambicans; women being charged for children's growth monitoring need to be substantiated and if true, urgent corrective measures should be taken.

\section{Acknowledgements}

We thank the Scottish Government for their financial support without which this study would not have taken place. Thanks also go to Mr Lungu, Mr Kasambara, and Mr Makumbi for their support in data collection. Special, acknowledgement should also go to the study participants at Gaga, Chithumba and Chang'ambika. 
Table 1: Recommendations

\begin{tabular}{|c|c|c|}
\hline Barrier & $\begin{array}{l}\text { Suggested } \\
\text { solutions by } \\
\text { study partici } \\
\text { pants }\end{array}$ & $\begin{array}{l}\text { Suggested } \\
\text { solutions by } \\
\text { study designers }\end{array}$ \\
\hline $\begin{array}{l}\text { Travelling long } \\
\text { distances to access } \\
\text { health services }\end{array}$ & $\begin{array}{l}\text { Establish more } \\
\text { outreach clinics }\end{array}$ & $\begin{array}{l}\text {-Establish more } \\
\text { Antenatal Care } \\
\text { Clinics. } \\
\text {-Establish more } \\
\text { birthing facilities } \\
\text { together with } \\
\text { established referral } \\
\text { links. } \\
\text {-Improve } \\
\text { transportation }\end{array}$ \\
\hline Lack of midwives & $\begin{array}{l}\text { Bring back Tradition } \\
\text { al Birth Attendants }\end{array}$ & $\begin{array}{l}\text {-Train more mobile } \\
\text { mid-wives } \\
\text {-Older Traditional } \\
\text { Birth Attendants to } \\
\text { assist in these clinics } \\
\text { in counseling, } \\
\text { monitoring and } \\
\text { regular checks. } \\
\text {-Improve working } \\
\text { environment and } \\
\text { salary structure. }\end{array}$ \\
\hline $\begin{array}{l}\text { Lack of or insufficient } \\
\text { items to be used } \\
\text { during delivery }\end{array}$ & & $\begin{array}{l}\text {-Form women's } \\
\text { saving groups to be } \\
\text { involved in IGA (e.g. } \\
\text { sewing warm } \\
\text { clothing for babies to } \\
\text { sell at an affordable } \\
\text { price, rearing goats, } \\
\text { chickens for meat } \\
\text { and egg sale). }\end{array}$ \\
\hline Long stay in hospital & & $\begin{array}{l}\text {-Encourage ANC } \\
\text { use in the proposed } \\
\text { outreach clinics. } \\
\text {-Improve referral } \\
\text { system in case of } \\
\text { emergency } \\
\text { (motorbike } \\
\text { ambulances ) } \\
\text {-High risk } \\
\text { pregnancies month. }\end{array}$ \\
\hline $\begin{array}{l}\text { Corrupt, rude and } \\
\text { disrespectful health } \\
\text { staff }\end{array}$ & $\begin{array}{l}\text { Government should } \\
\text { bring health staff } \\
\text { with good attitude } \\
\text { and who are not } \\
\text { corrupt }\end{array}$ & $\begin{array}{l}\text {-Frequent } \\
\text { supervisory visits to } \\
\text { health facilities. } \\
\text {-Supervisory visits to } \\
\text { include community } \\
\text { members' views. } \\
\text {-Introduce name tag } \\
\text { wearing when staff is } \\
\text { on duty. } \\
\text { - Health staff to be } \\
\text { sensitized on patient } \\
\text { rights and what the } \\
\text { patients can do if } \\
\text { their rights are } \\
\text { violated. }\end{array}$ \\
\hline
\end{tabular}

References

1. WHO, 2010. Trends in Maternal Mortality: 1990-2008. Estimates developed by WHO, UNICEF, UNFPA, and The World Bank. WHO Press, World Health Organization, Geneva. Available: http://www.who. int/reproductivehealth, accessed on 6th December, 2010.

2. Ordonez E., (2008). Rural Women and the Millenium Development Golas. Article Source: Philippine Daily Enquirer. Available http:// business.inquirer.net/money/features/view/20008314-124617/ruralwomen-andmillenium- devt-goals

3. United Nations (2010). The Millenium Development Goals Report. Available: http//www. Accessed 16th December, 2010.

4. UNICEF, Malawi, Statistics: 1998-2007. Available:http:/ www.unicef. org/infobycountry/Malawi_statistics.html accssed on 17/12/2010.

5. ORC Macro. Demographic and Health survey: Malawi 2007. Calverton, MD, ORC Macro, 2007

6. Pearson M., 2010. Impact Evaluation of the Sector Wide Approach (SWAp), Malawi. DFID Human Development Resource Centre.

7. Republic of Malawi, Ministry of Health, (2005). Road Map for Accelerating the reduction of Maternal and Neonatal Mortality and Morbidity in Malawi.

8. Masangwi S.J. (2010). Scotland Chikhwawa Health Initiative Safe Motherhood Project, Chapananga, Chikwawa District, Malawi. Unpublished report sponsored by The Scottish Government.

9. Tones K, Green J. (2004). Health Promotion: Planning and Strategies, Sage Publications.

10. Hofman J.J., Sibande Ndemera M., (2005). Review of community based maternal deaths in Mangochi. Malawi Medical Journal; 17(3):8184.

11. Koblinsky, M. A. (2003). Reducing Maternal Mortality. Learning from Bolivia, China, Egypt, Honduras, Indonesia, Jamaica, and Zimbabwe. Washington, D.C.: The World Bank.

12. Kafulafula U.K., Hami M., Chodzaza E., (2005). The Challenges facing nurse-midwives in working towards Safe Motherhood in Malawi. Malawi Medical Journal; 17(4):125- 127.

13. Gerein N, Green A, Pearson S, (2006). The Implications of Shortages of Health Professionals for Maternal Health in Sub-saharan Africa. Reproductive Health Matters; 14(27): 40-50.

14. Midhet, F., Becker S., and Berendes H. W., (1998). Contextual determinants of maternal mortality in rural Pakistan. Social Science \& Medicine, 46, 1587-1598.

15. International Forum for Rural Transport and Development (IFRTD), 2008. "Midwives on Motorbikes." Available: http://www.ifrtd.org accessed on 6th Dececember, 2010. 